Research Article

\title{
Mechanical Mechanism and Propagation Law of Fissure-Tip Cracks of Large-Size Rock Specimens with Two Precut Fissures
}

\author{
Liming Yin, ${ }^{1}$ Ming Li $\mathbb{D},{ }^{2}$ Wenbin Sun $\mathbb{D}^{1},{ }^{1}$ Juntao Chen, ${ }^{1}$ Bin Liu, ${ }^{2}$ and Ziqi Wang ${ }^{1}$ \\ ${ }^{1}$ College of Energy and Mining Engineering, Shandong University of Science and Technology, Qingdao, 266590, China \\ ${ }^{2}$ College of Safety and Environmental Engineering, Shandong University of Science and Technology, Qingdao, 266590, China
}

Correspondence should be addressed to Wenbin Sun; swb@sdust.edu.cn

Received 28 August 2020; Revised 22 October 2020; Accepted 22 March 2021; Published 1 April 2021

Academic Editor: Antonio Batista

Copyright (c) 2021 Liming Yin et al. This is an open access article distributed under the Creative Commons Attribution License, which permits unrestricted use, distribution, and reproduction in any medium, provided the original work is properly cited.

The rock is a kind of geological medium with damages of different degrees including fissures, faults, joints, and other structural defects. Many underground rock engineering projects, such as mining and tunnel excavation, can break the three-dimensional stress balance state of rock mass and make it subject to two-dimensional or even one-dimensional stress, thus inducing stress concentration which leads to rapid failure. In order to investigate the failure law of the rock mass with such defects under twodimensional stress, based on the similarity theory, we first prepared rocklike specimens with fissures featuring actual mechanical properties and then systematically analyzed the fissure-tip crack propagation and specimen failure law and mechanical mechanism under two-dimensional stress in view of the stress field theory. The results demonstrate that with the increase of load, the microcracks developed and propagated gradually, during which a number of branch paths were generated from the fissure tips of the specimens; the upper and lower cracks were connected first due to the main crack propagation, forming a sliding surface which caused the failure of the specimens, and the strengths of the specimens also fluctuated according to the different combinations of the fissure dip angles and rock bridge dip angles. In view of acoustic emission (AE), we calculated and obtained the spatial positions of stress peaks in each direction at the fissure tips; through comparison and analysis, the angle corresponding to the negative angle peak of the maximum circumferential tensile stress and the maximum radial tensile stress is basically the same as the angle of the main crack propagation direction generated from the preexisting fissure; it can be inferred that the tensile stress is the main stress inducing crack initiation and specimen failure, which is consistent with the physical characteristics of rock (resistant to compression but not tension). This may serve as a guidance for judging the direction along which new cracks are generated in a rock mass with double structural planes.

\section{Introduction}

As a large number of engineering projects across the globe have demonstrated, brittle fractures and other phenomena related to rock mechanics during the process of underground projects, such as deep roadway surrounding rock collapse, slope sliding, surface subsidence, are final macroqualitative changes of crack generation, propagation, evolution, and penetration inside the rock mass. It is much easier for cracks inside jointed rock mass under high geostress to slide and penetrate. As mining goes increasingly deeper underground, the excavation of deep jointed rock mass induces the strain energy release. Under the environment of complex high geostress, new cracks will be generated by rapid energy release at the joint tip, which can lead to rock mass failure after crack propagation and interjoint penetration, thus resulting in financial losses and casualties $[1,2]$.

Among the studies on fissure propagation and evolution, Sun et al. classified crack propagation by investigating the stress characteristics of the crack surface based on fracture mechanics [3]. Through uniaxial compression experiments on rock-like materials with different prefabricated crack dip angles and rock bridge dip angle, Pu et al. analyzed the crack penetration mode under different crack angles; and on the basis of the stress-strain curve and macrofailure morphological characteristics during the whole experiment, they also investigated the instability failure mechanism of these 
rock-like materials [4]. Yin et al. employed AE for real-time tracking in an experimental study on the crack propagation and evolution process of large-size rock specimens under three-dimensional stress and osmotic water pressure [5].

Among the studies on the stress field at the crack tip, Irwin explored the stress analysis of cracks, put forward the concept of stress intensity factor, and classified the cracks into type I, type II, type III, and the mixed type formed by the combination of these three types [6]. Li et al. established the damage and fracture mechanics model of rock materials with preset cracks under the combined action of compression-shear stress field and seepage field, and the evolution equation of stress intensity factor at the crack tip, and proposed that the stress intensity factor at the crack tip can be adopted as the crack initiation criterion for judging the cracks in compression-shear rock [7]. Some other scholars, considering that the fractured rock mass is actually in a multidimensional stress environment, investigated characteristics of stress change during crack initiation and the change law of specimen fracture process through uniaxial and biaxial loading failure tests on gypsum specimens with preset fissures [8].

To sump up, many scholars have made great achievements and gained practical experience in the studies on crack propagation and fracture mechanism of fractured rock mass [9-11]. However, there is still a lack of research regarding prefabricated cracks with different geometric parameters under two-dimensional stress, the direction of crack propagation, and the stress field at the crack tip as previous literature analyzed crack evolution mainly according to crack development morphology on the macroscale. The current research, based on previous studies, rock mechanics, and fracture mechanics, investigated the stress distribution at the crack tip through loading tests on rock-like specimens with different combinations of crack dip angles, rock bridge dip angles and rock bridge lengths. Moreover, by employing $\mathrm{AE}$ for real-time tracking and positioning of crack initiation, propagation, penetration, and specimen failure, it systematically analyzed the consistency between specimen-end stress concentration and crack propagation and evolution.

\section{Analysis of Crack Propagation Mechanism and Failure of Rock Mass with Dual Structural Plane}

2.1. Failure Mechanism of Structural Plane Rock Mass. Rock mass is a geological body composed of rock blocks and structural planes, and its strength is thus controlled by the strength of rock blocks and structural planes and their combination mode (rock mass structure) [12]. In general, the strength of the rock mass is different from that of the rock block or the structural plane. If the rock mass structure is complete without a structural plane, the strength of the rock mass is roughly equal to that of the rock block. If the rock mass will slide along a structural plane, the strength of the rock mass is completely controlled by that structural plane. This paper is based on the simulation of jointed rock mass with two precut fissures, on which the crack propagation and failure are affected by the properties of rock materials and also the characteristics of the structural planes [13-15].

Taking the strength analysis of a single structural plane as an example, we define the angle between the normal of the structural plane and the direction of the maximum principal stress as $\beta$, then based on the Mohr's circle theory, the normal stress $\sigma_{\beta}$ and shear stress $\tau_{\beta}$ on the structural plane are, respectively, as follows:

$$
\begin{aligned}
& \sigma_{\beta}=\frac{1}{2}\left(\sigma_{1}+\sigma_{2}+\left(\sigma_{1}-\sigma_{2}\right) \cos 2 \beta\right) \\
& \tau_{\beta}=\frac{1}{2}\left(\sigma_{1}-\sigma_{2}\right) \sin 2 \beta .
\end{aligned}
$$

According to the Mohr-Coulomb criterion, the shear strength of the structural plane is as follows:

$$
\tau=c+\sigma \tan \varphi
$$

Here, $c$ and $\varphi$ are the bonding force and the internal friction angle of the structural plane, respectively. Substitute (1) into (2) and set $\tau^{\prime}=\tau_{\alpha}-\left(c+\sigma_{\alpha} \tan \varphi\right)$. Then, if the external stress reaches the ultimate strength of the fissure surface, the cracks will be initiated, and at this moment, the mechanical condition is $\tau^{\prime}$, that is,

$$
\begin{aligned}
\frac{\sigma_{1}-\sigma_{2}}{2}(\sin 2 \beta-\tan \varphi \cos 2 \beta) & >c-\frac{\left(\sigma_{1}+\sigma_{2}\right) \tan \varphi}{2} \\
\sin (2 \beta-\varphi) & >\frac{2 c \cos \varphi-\left(\sigma_{1}+\sigma_{2}\right) \sin \varphi}{\sigma_{1}-\sigma_{2}} .
\end{aligned}
$$

We can obtain the following:

$$
\beta>\frac{1}{2}\left(\arcsin \frac{2 c \cos \varphi-\left(\sigma_{1}+\sigma_{2}+2 P\right) \sin \varphi}{\sigma_{1}-\sigma_{2}}+\varphi\right) .
$$

And when $\beta$, the angle between the outer normal $n$ of the structural plane and the horizontal direction, satisfies (4), the crack surface will suffer sliding shear failure. The failure and failure direction of the specimens can be judged according to the relationship between the Mohr strength envelope and the Mohr's circle.

For the rock mass with two or more groups of structural planes, the single structural plane theory can be used step by step to obtain the Mohr strength envelope and the Mohr's circle when each group of structural planes exist separately, as shown in Figure 1. And the direction of specimen failure is determined by the angle between the maximum principal stress $\sigma_{1}$ and the structural plane [12].

If $\beta$, the angle between the first group of structural planes and $\sigma_{1}$, satisfies $2 \beta_{1}^{\prime} \leq 2 \beta^{\prime} \leq 2 \beta_{2}^{\prime}$, the rock mass will fail along the first structural plane. Otherwise, it will not; if $\beta$, the angle between the second group of structural planes and $\sigma_{1}$, satisfies $22 \beta_{1}^{\prime \prime} \leq 2 \beta^{\prime \prime} \leq 2 \beta_{2}^{\prime \prime}$, the rock mass will fail along the second group of structural planes. If $\beta$, the angle between the structural plane and $\sigma_{1}$ is not in this range, the rock mass will fail along the rock section $\beta_{0}=(\pi / 4)+(\varphi / 2)$. 


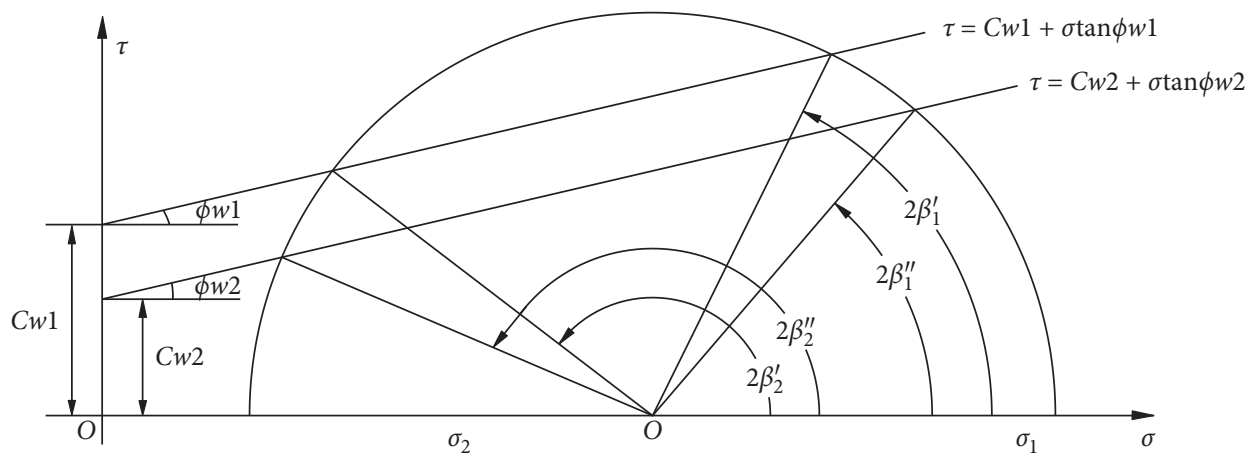

FIGURE 1: Strength analysis of rock mass with a dual structural plane.

2.2. Criterion of Crack Propagation under Stress. When the stress state of the rock mass changes, the stress concentration will appear at the fissure tip; if the tip stress exceeds the shear strength of the fissure, new cracks will be initiated as the primary fissure propagates [16]. According to related theories of fracture mechanics [17], whether the fissure propagates or not depends on the stress near the fissure tip and the length of the fissure. The cracks, which are subjected to the stresses at different geometric positions on the crack surface, can be divided into types I, II, and III with different tearing characteristics. In engineering projects, the fracture surface, under external load, is subjected to the joint action of normal stress and shear stress, which induces gradual propagation of internal cracks, thus causing the mixed failure of rock mass [18]. When the force on the crack surface is vertical tensile stress or compressive stress, the cracks will propagate into I-II tension-shear or compression-shear mixed cracks.

The specimens with two fissures fail mainly in the form of rock bridge penetration and in modes of shear failure, tension-shear mixed failure and wing crack propagation failure, as shown in Figure 2.

\section{Test on the Propagation and Evolution Law of Rock-like Specimens with Two Fissures}

3.1. Specimen Preparation. In order to investigate the crack propagation and mechanical mechanism of rock-like twofissure specimens with different combinations of crack dip angles and rock bridge dip angles under biaxial loading, we referred to related literature on the preparation of rock-like materials and learned that gypsum composites are widely used in the model test of rock-like materials, and many Chinese scholars have carried out their material proportion experiments $[19,20]$. Based on the existing research results, the mass ratio of the model gypsum, microsilicon powder, and water used for material preparation is $165: 2: 70$. This material shares great similarities with the brittle rocks in macroproperties [21]. According to ISRM standardized test requirement [22], we measured and obtained the material parameters, as shown in Table 1.

The mold used in this test is a standard concrete mold with a dimension of $300 \mathrm{~mm} \times 150 \mathrm{~mm} \times 150 \mathrm{~mm}$. For the preparation of the two fissures, we used a plastic sheet
$(250 \mathrm{~mm} \times 60 \mathrm{~mm} \times 3 \mathrm{~mm})$ which was extracted from the specimen before its solidification. After that, two fissures $(60 \mathrm{~mm} \times 3 \mathrm{~mm} \times 150 \mathrm{~mm})$ were obtained.

In order to investigate the law and mechanical mechanism of crack propagation and evolution at the fissure tip, we carried out a similar simulation test in the laboratory, during which we prefabricate the two-fissure specimen with three changes of the fissure dip angle $\alpha$ of $30^{\circ}, 45^{\circ}$, and $60^{\circ}$, and two changes of the rock bridge ( $80 \mathrm{~mm}$ long) dip angle $\beta$ of $120^{\circ}$ and $150^{\circ}$. The image of the specimen is shown in Figure 3, and the fissure parameters are shown in Table 2.

3.2. Loading Mode. We utilized the true triaxial test system of coupled stress-seepage developed by Shandong University of Science and Technology [5]. While carrying out the loading test on the specimens, we adopted PCI-2 AE monitoring system for real-time positioning of the loading process and fissure propagation path of the specimens. This test system can realize the fissure propagation and evolution process and real-time monitoring of rock-like specimens under axial and lateral loading and effectively reduce the influence on rock mechanical properties in terms of scale effect. The arrangement of AE sensors is shown in Figure 3.

During the test, we exerted biaxial compression on the specimens using force control, and the loading rate is $0.2 \mathrm{kN} /$ s. We applied axial loading on the specimen along the $\sigma 1$ direction until it failed, and the confining pressure of $1 \mathrm{MPa}$ on it along the $\sigma_{2}$ direction, as shown in Figure 4. Meanwhile, we used the PCI-2 ae monitoring system for real-time positioning of the loading process and crack propagation path of the rock-like specimens. The whole loading process was recorded using a camera.

\section{Specimen Failure and Crack Propagation Law}

4.1. Specimen Loading and Fissure Propagation. During the biaxial compression test on the specimens, we turned on the tester and the camera synchronously to record the failure stages of the specimens in real time. After the test, we selected the images of the specimen loading at different angles and stages (see Figure 5) to summarize the numbers, lengths, and positions of major cracks (see Table 3 ) and analyze the failure process. 


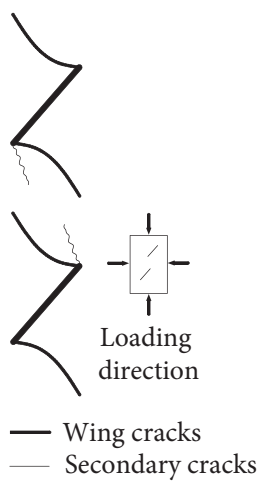

(a)

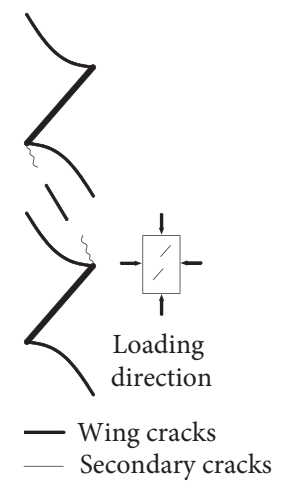

(b)

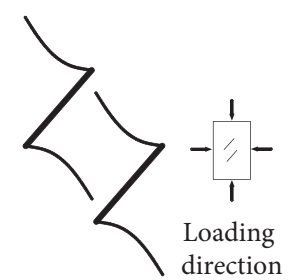

- Wing cracks

- Secondary cracks

(c)

Figure 2: Failure modes of rock specimens with two fissures under biaxial loading. (a) Shear failure (b) Tension-shear mixed failure (c) Wing crack propagation failure.

TABLe 1: Physical properties of experimental specimens.

\begin{tabular}{lcccc}
\hline $\begin{array}{l}\text { Uniaxial compressive strength } \sigma \\
(\mathrm{MPa})\end{array}$ & $\begin{array}{c}\text { Tensile strength } \sigma \\
(\mathrm{MPa})\end{array}$ & $\begin{array}{c}\text { Elastic modulus } E \\
(\mathrm{GPa})\end{array}$ & $\begin{array}{c}\text { Cohesive force } c \\
(\mathrm{MPa})\end{array}$ & $\begin{array}{c}\text { Internal friction angle } \\
\left({ }^{\circ}\right)\end{array}$ \\
\hline 23.13 & 2.76 & 4.25 & 3.60 & $31.2^{\circ}$ \\
\hline
\end{tabular}

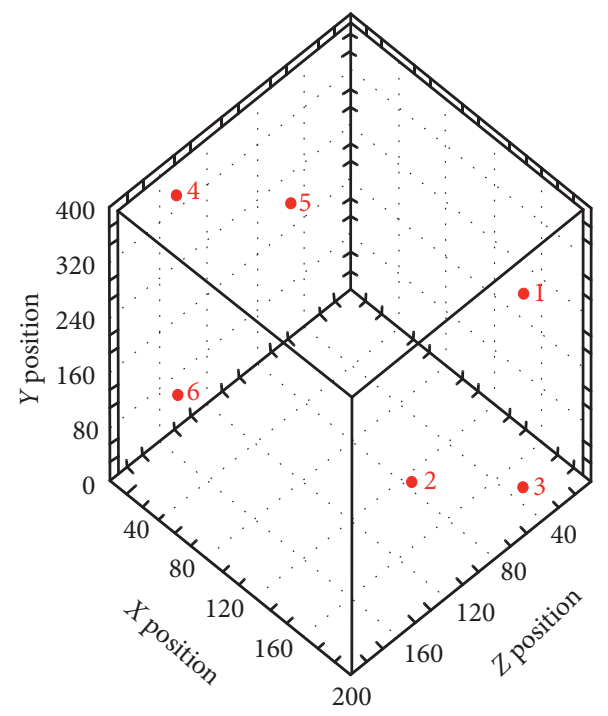

Figure 3: The arrangement of AE sensors.

TABLE 2: Specimen crack parameters.

\begin{tabular}{|c|c|c|c|c|}
\hline Specimen no. & Crack dip angle $\left({ }^{\circ}\right)$ & Rock bridge dip angle $\left({ }^{\circ}\right)$ & Crack length $(\mathrm{mm})$ & Rock bridge length (mm) \\
\hline$A-1$ & $30^{\circ}$ & $120^{\circ}$ & \multirow{6}{*}{60} & \multirow{6}{*}{80} \\
\hline$A-2$ & $30^{\circ}$ & $150^{\circ}$ & & \\
\hline$A-3$ & $45^{\circ}$ & $120^{\circ}$ & & \\
\hline$A-4$ & $45^{\circ}$ & $150^{\circ}$ & & \\
\hline$A-5$ & $60^{\circ}$ & $120^{\circ}$ & & \\
\hline$A-6$ & $60^{\circ}$ & $150^{\circ}$ & & \\
\hline
\end{tabular}

4.2. AE Characteristics. During the loading, the number of the AE events was small at first and gradually grew around the fissures in the middle of the specimens; when the axial loading reached about $30 \%$ of $\sigma_{1}$, the microcracks began to appear and the number of the AE events rose rapidly around the fissures and on the propagation path; when it reached about $90 \%$ of $\sigma_{1}$, which is near the critical state of failure, the number of the AE events increased sharply with a sliding 


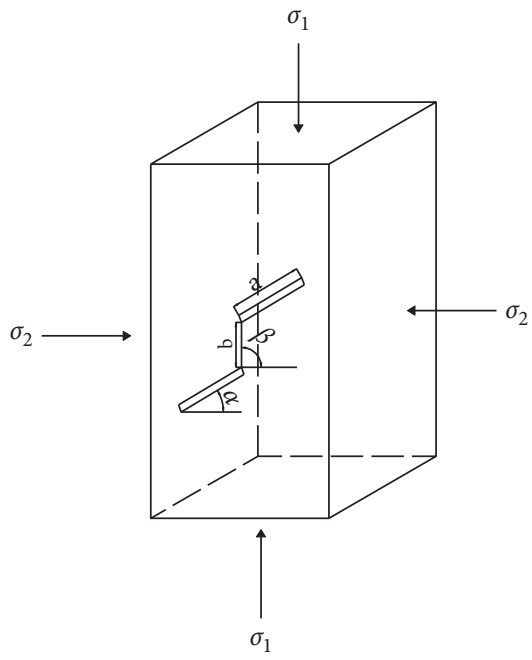

FIGURE 4: Diagram of specimen loading. $\alpha$-Fissure dip angle, $\beta$-rock bridge dip angle, a-fissure length, b-rock bridge length, $\sigma_{1}$-axial stress, $\sigma_{2}$-lateral pressure.
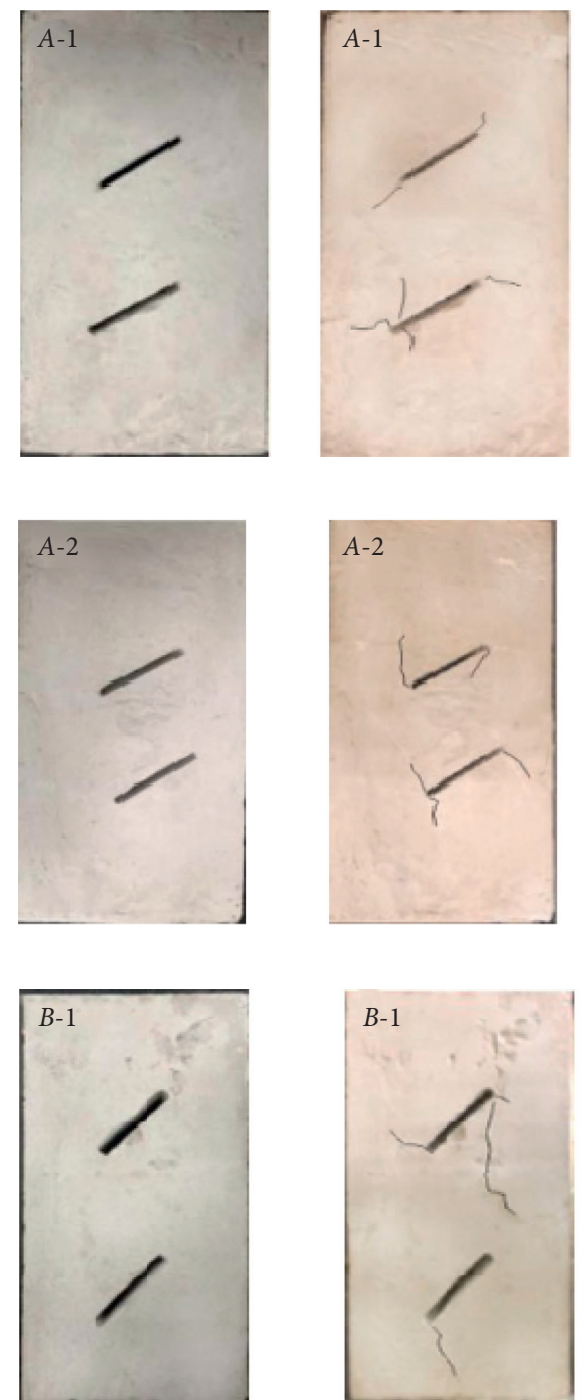

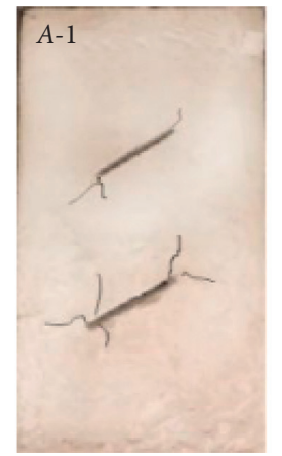

(a)
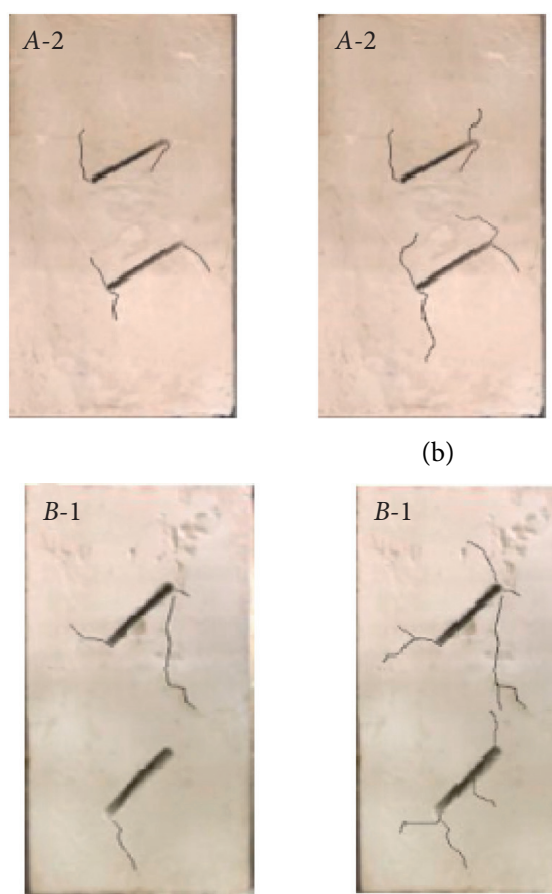

(b)
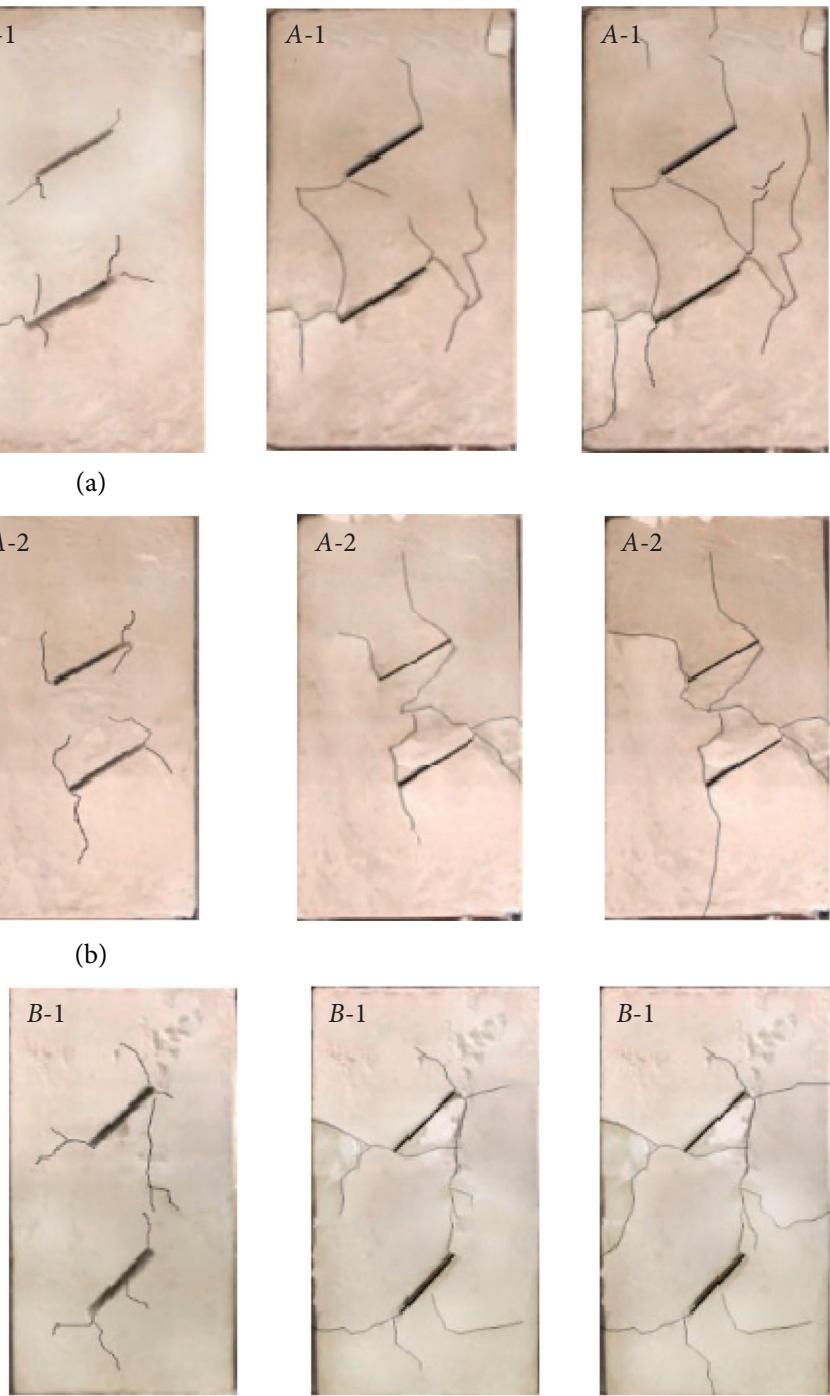

(c)
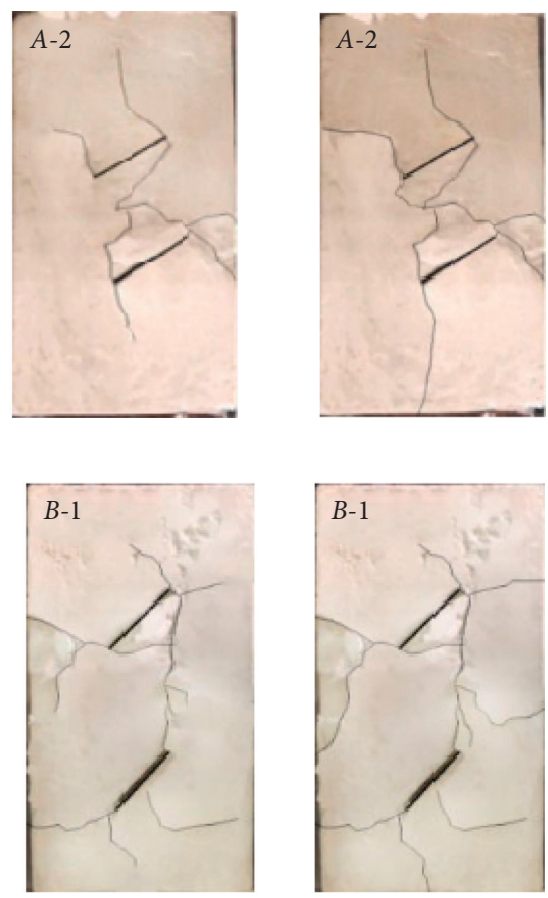

FIgURE 5: Continued. 

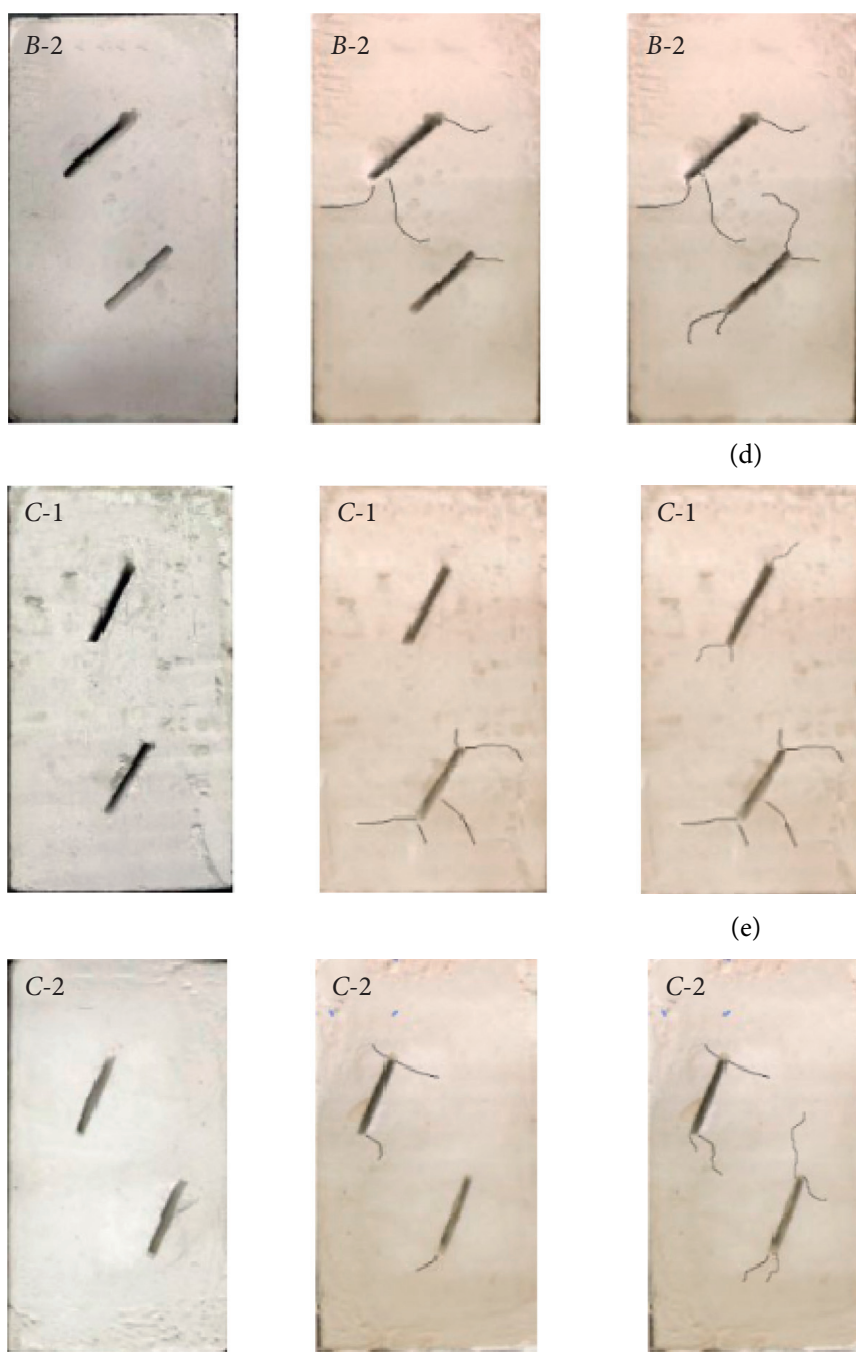
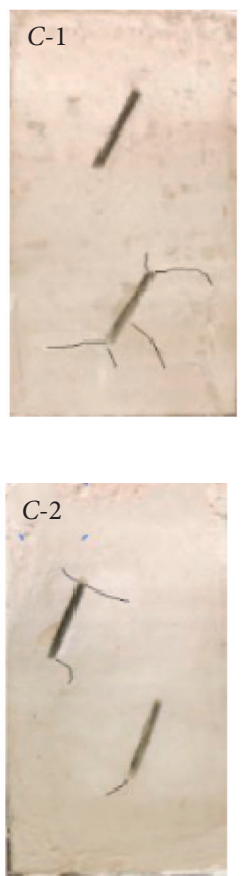

(d)
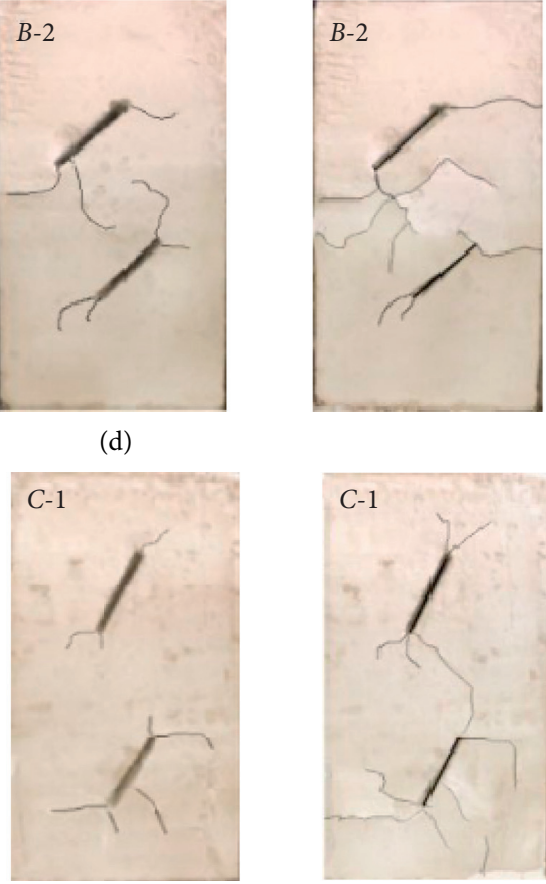

(e)

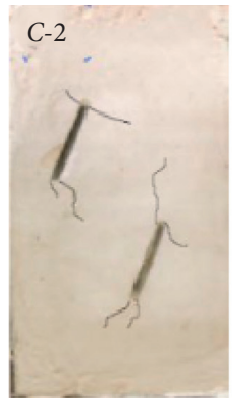

(f)
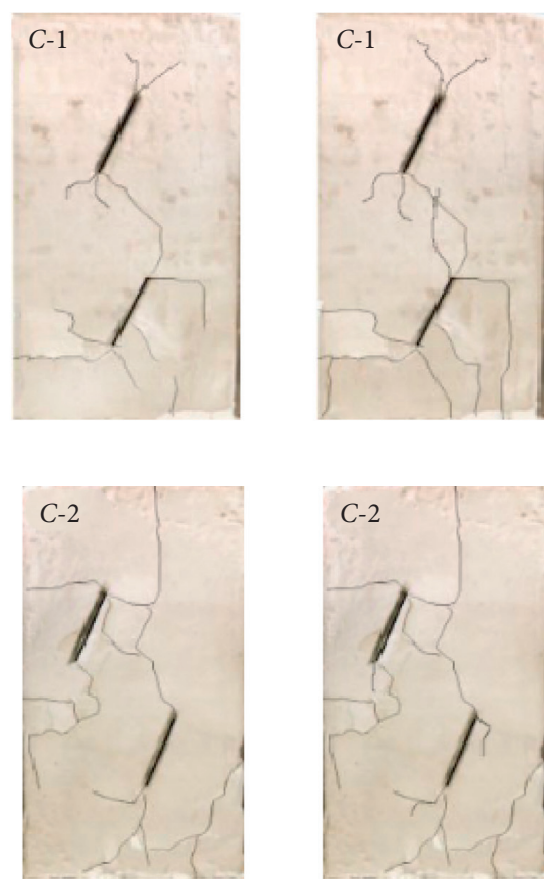

FIGURE 5: Major crack propagation during the specimen failure. (a) Fissure propagation on the specimen $A$-1. (b) Fissure propagation on the specimen $A$-2. (c) Fissure propagation on the specimen $B$-1. (d) Fissure propagation on the specimen $B$-2. (e) Fissure propagation on the specimen $C-1$. (f) Fissure propagation on the specimen $C-2$.

surface generated by the fissure penetration, finally leading to the failure of the specimen [23]. In view of the $\mathrm{AE}$ characteristics, we monitored the stress-strain of each specimen synchronously and drew corresponding stresstime curves, as shown in Figure 6.

Based on the stress-strain curves and the AE characteristics, the following can be found:

(a) We monitored the axial stress of each specimen which was about to fail, which is the compressive strength, as shown in Figure 5. The compressive strengths of group- $\mathrm{A}$, group- $\mathrm{B}$, and group-C specimens are $5.57 \mathrm{MPa}$ and $5.9 \mathrm{MPa}, 4.1 \mathrm{MPa}$ and $5.42 \mathrm{MPa}$, and $4.56 \mathrm{MPa}$ and $4.03 \mathrm{MPa}$, respectively, each of which is much lower than that of the control specimen. The results showed that the overall strength of the specimens with the fissure dip angles of $30^{\circ}$ and $45^{\circ}$ increases with the increase of rock bridge dip angle, while the overall strength of the specimens with fissure dip angle of $60^{\circ}$ decreases with the increase of the inclination angle of the rock bridge. It can be deduced that the overall compressive strength of the two-fissure specimens is closely related to the fissure dip angle and the rock bridge dip angle, and the critical angle of the fissure ranges between $45^{\circ}$ and $60^{\circ}$.

(b) All the specimens with six types of precut dip angles have experienced the whole process of microcrack initiation, development, penetration, and specimen failure (see Figure 5). According to the data in Table 3 , for $A-1$, the wing cracks developed at the inner tips of the upper and lower fissures, with the rock bridge penetrated and the angle $-110^{\circ}$ between the penetrated crack and fissure; for $A-2$, the wing cracks developed slowly at the inner tip of the upper fissure and along the direction of $-105^{\circ}$ at the inner tip of the lower fissure without the rock bridge penetrated, and 
TABLE 3: The numbers, lengths, and positions of the major cracks.

\begin{tabular}{|c|c|c|c|c|c|c|}
\hline Specimen & $\begin{array}{l}\text { Inner tip } \\
\text { crack }\end{array}$ & $\begin{array}{r}\text { Total } \\
\text { length } \\
(\mathrm{mm})\end{array}$ & Numbers & $\begin{array}{c}\text { Angles between the wing } \\
\text { cracks and the fissure } \\
\text { plane }\left({ }^{\circ}\right)\end{array}$ & $\begin{array}{l}\text { Angles between the secondary } \\
\text { coplanar cracks and the fissure } \\
\text { plane }\left(^{\circ}\right)\end{array}$ & $\begin{array}{l}\text { Angles between the secondary } \\
\text { inclined cracks and the fissure } \\
\text { plane }\left({ }^{\circ}\right)\end{array}$ \\
\hline \multirow{2}{*}{ A-1 } & $\begin{array}{l}\text { Upper } \\
\text { crack }\end{array}$ & 145 & 2 & -112 & -10 & - \\
\hline & $\begin{array}{l}\text { Lower } \\
\text { crack }\end{array}$ & 284 & 3 & $-106,-45$ & - & 83 \\
\hline \multirow{2}{*}{$A-2$} & $\begin{array}{l}\text { Upper } \\
\text { crack }\end{array}$ & 108 & 2 & -70 & - & 92 \\
\hline & $\begin{array}{l}\text { Lower } \\
\text { crack }\end{array}$ & 140 & 3 & -105 & 11 & 85 \\
\hline \multirow{2}{*}{$B-1$} & $\begin{array}{l}\text { Upper } \\
\text { crack }\end{array}$ & 152 & 2 & -135 & - & 150 \\
\hline & $\begin{array}{l}\text { Lower } \\
\text { crack }\end{array}$ & 124 & 2 & $-62,-81$ & - & - \\
\hline \multirow{2}{*}{$B-2$} & $\begin{array}{l}\text { Upper } \\
\text { crack }\end{array}$ & 82 & 2 & $-94,-78$ & - & - \\
\hline & $\begin{array}{l}\text { Lower } \\
\text { crack }\end{array}$ & 126 & 2 & $-108,65$ & - & - \\
\hline \multirow{2}{*}{$C-1$} & $\begin{array}{l}\text { Upper } \\
\text { crack }\end{array}$ & 138 & 3 & $-30,-85$ & - & 25 \\
\hline & $\begin{array}{l}\text { Lower } \\
\text { crack }\end{array}$ & 145 & 3 & -66 & -10 & -62 \\
\hline \multirow{2}{*}{$C-2$} & $\begin{array}{l}\text { Upper } \\
\text { crack }\end{array}$ & 87 & 2 & $-20,-72$ & - & - \\
\hline & $\begin{array}{l}\text { Lower } \\
\text { crack }\end{array}$ & 120 & 2 & -55 & - & 94 \\
\hline
\end{tabular}

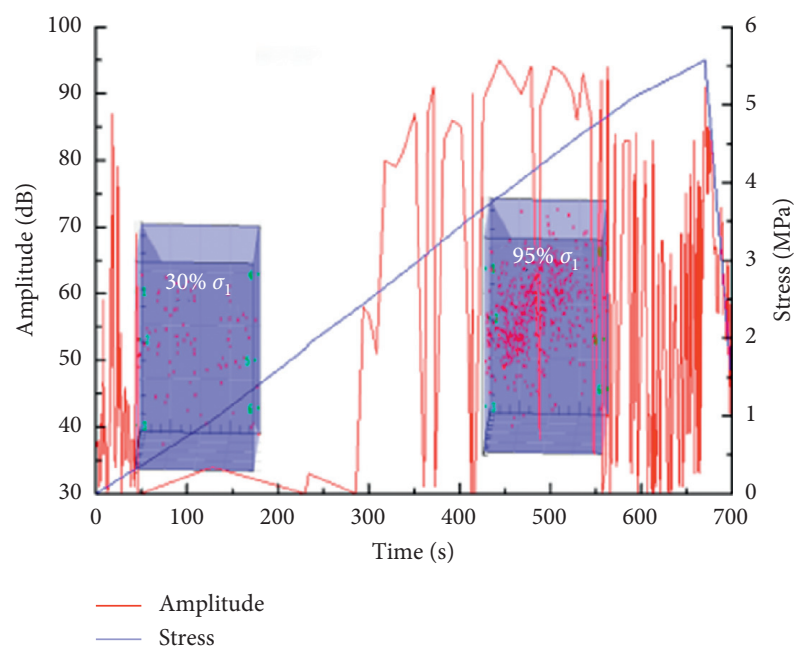

(a)

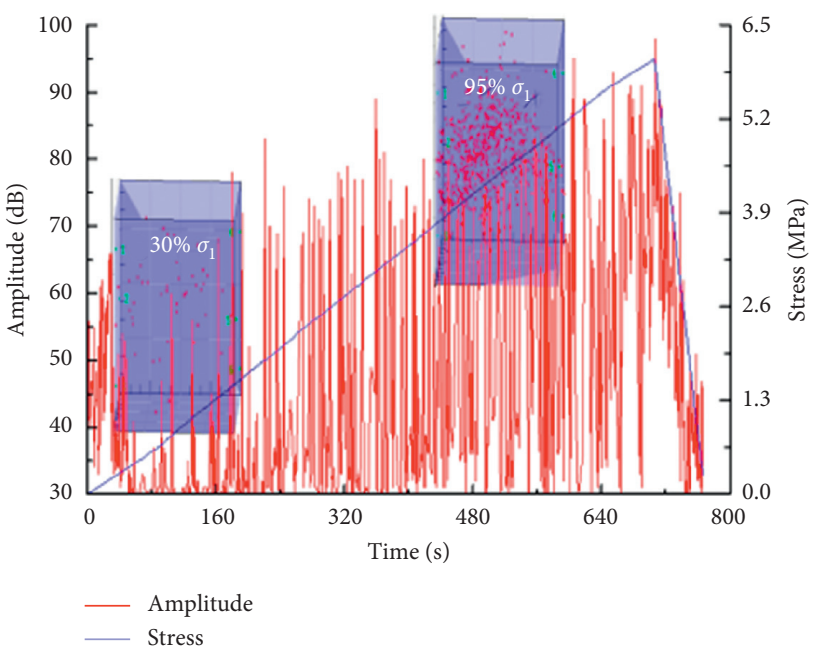

(b)

Figure 6: Continued. 


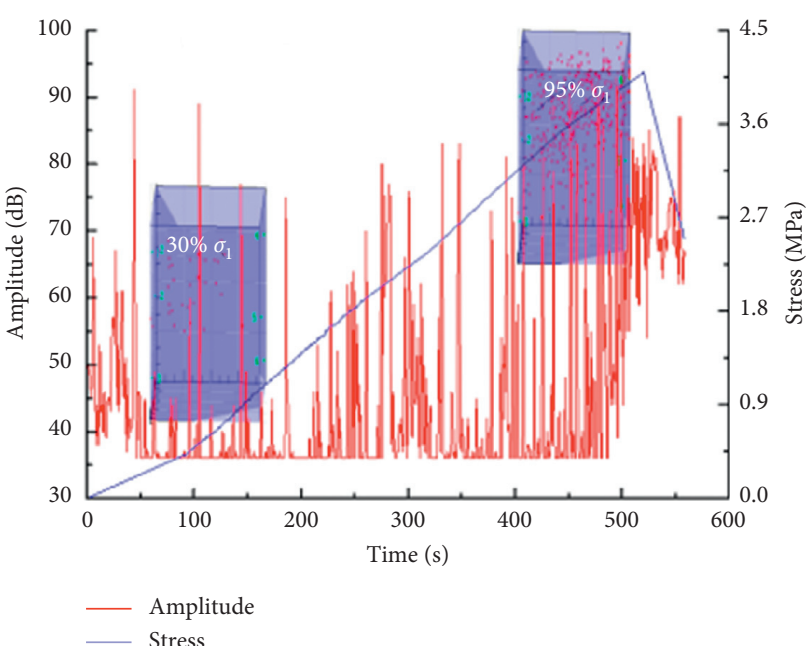

(c)

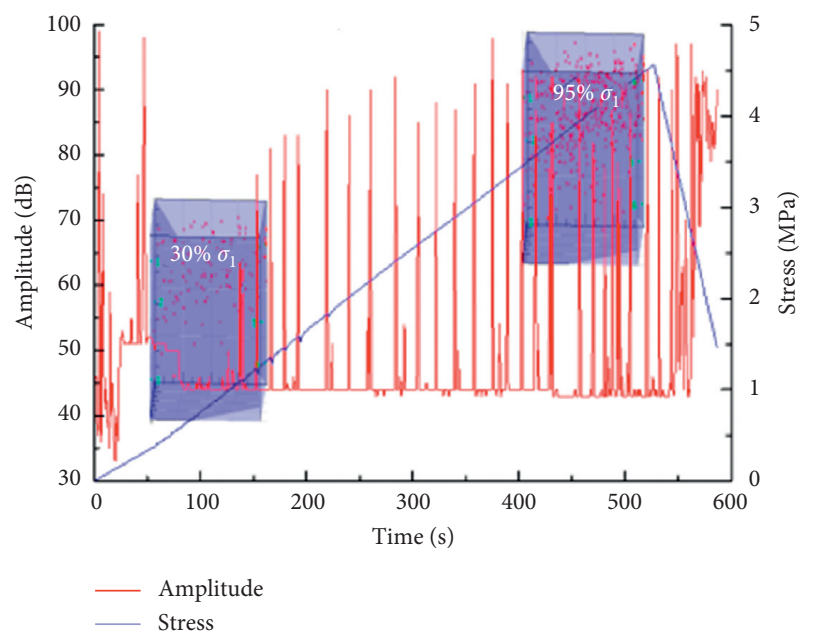

(e)

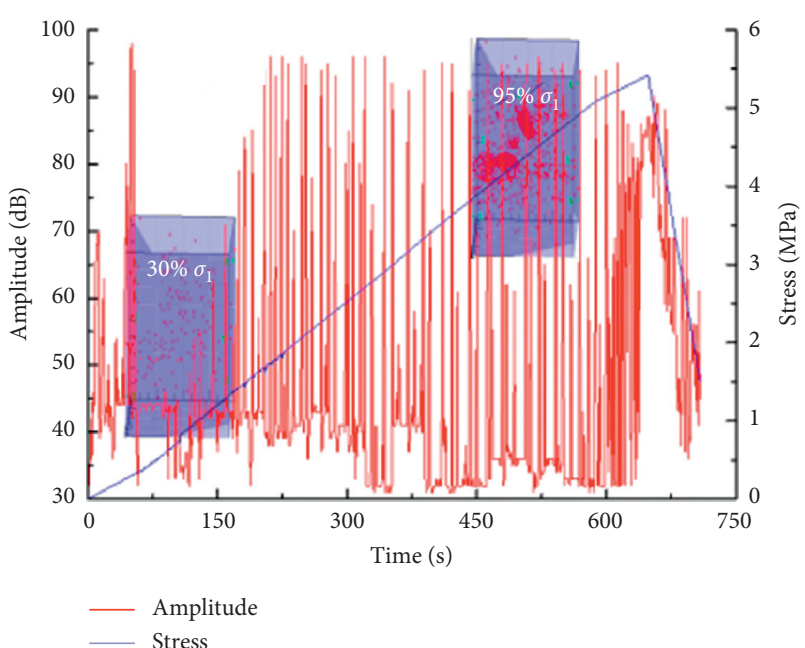

(d)

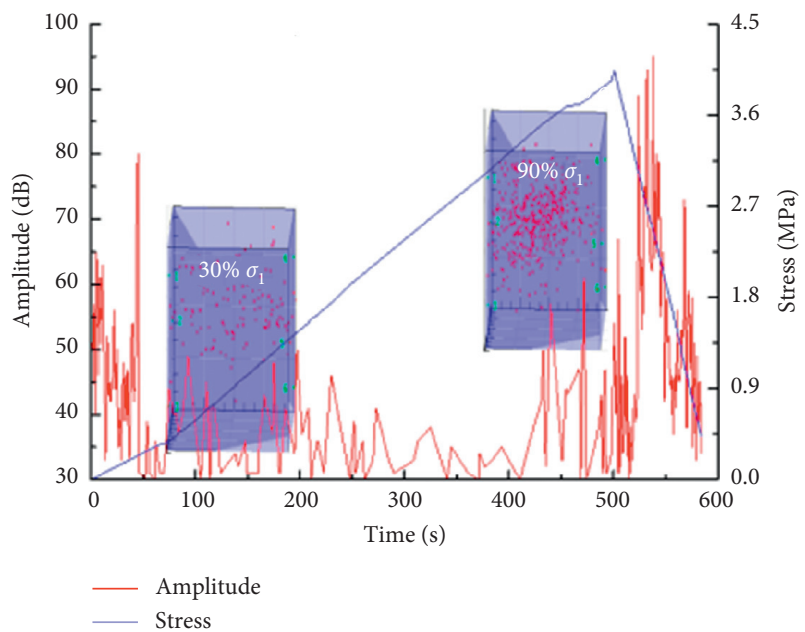

(f)

Figure 6: Stress-time curves and spatial distribution of AE events at different stress levels: (a) $A-1$, (b) $A-2$, (c) $B-1$, (d) $B-2$, (e) $C-1$, and (f) C-2.

the antiwing cracks at the outer tip of the upper fissure are penetrated to those at the outer tip of the lower fissure; for $B$ - 1 , the wing cracks generated at the inner tip of the lower fissure connected to the antiwing cracks at the outer tip of the upper fissure, with the fissures penetrated and the crack angle of about $-62^{\circ}$; for $B-2$, the wing cracks generated at the inner tip of the lower fissure propagated upward and connected to the coplanar shear cracks at the inner tip of the upper fissure, with the rock bridge penetrated at an angle of about $-100^{\circ}$; for $C$ - 1 , the wing cracks generated at the inner tip of the upper fissure propagated and connected to the cracks at the inner tip of the lower crack, with the rock bridge penetrated which had an angle of about $-75^{\circ}$; for $C-2$, the cracks at the outer tip of the upper fissure gradually propagated to the boundary, without the rock bridge penetrated, and the antiwing cracks at the outer tip of the upper fissure connected to the wing cracks at the lower boundary with an angle of about $55^{\circ}$. (c) As can be seen from Figure 5, when the axial loading reached about $30 \%$ of $\sigma_{1}$, the microcracks began to appear; when it reached about $70 \%$ of $\sigma_{1}$, the cracks had fully propagated with the types, numbers, and lengths increasing significantly; when it reached about $90 \%$ of $\sigma_{1}$, it was near the critical state of specimen failure, with the upper and lower fissures penetrated in different ways.

\section{Stress Field Distribution at the Tip of the Fissures and Their Propagation Law}

The analysis of the test results reveals that most specimens failed mainly under the combination of compression-shear and tension-shear with wing cracks, inclined shear cracks, and coplanar shear cracks generated while the $A-2$ and $B-2$ specimens failed mainly under the compression-shear with wing cracks and inclined shear cracks generated. The fissures in the process of the specimen failure belong to the above- 

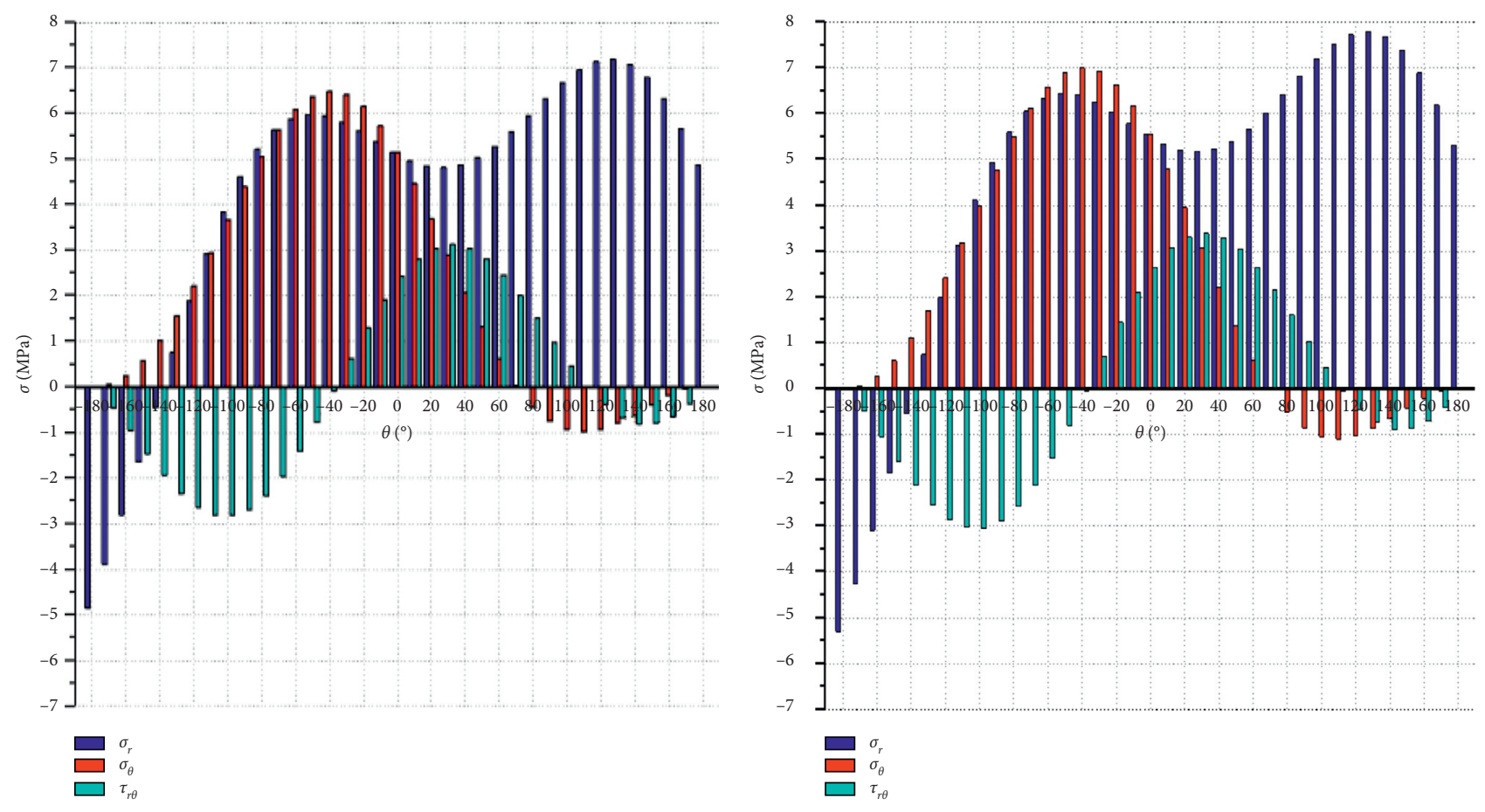

(a)
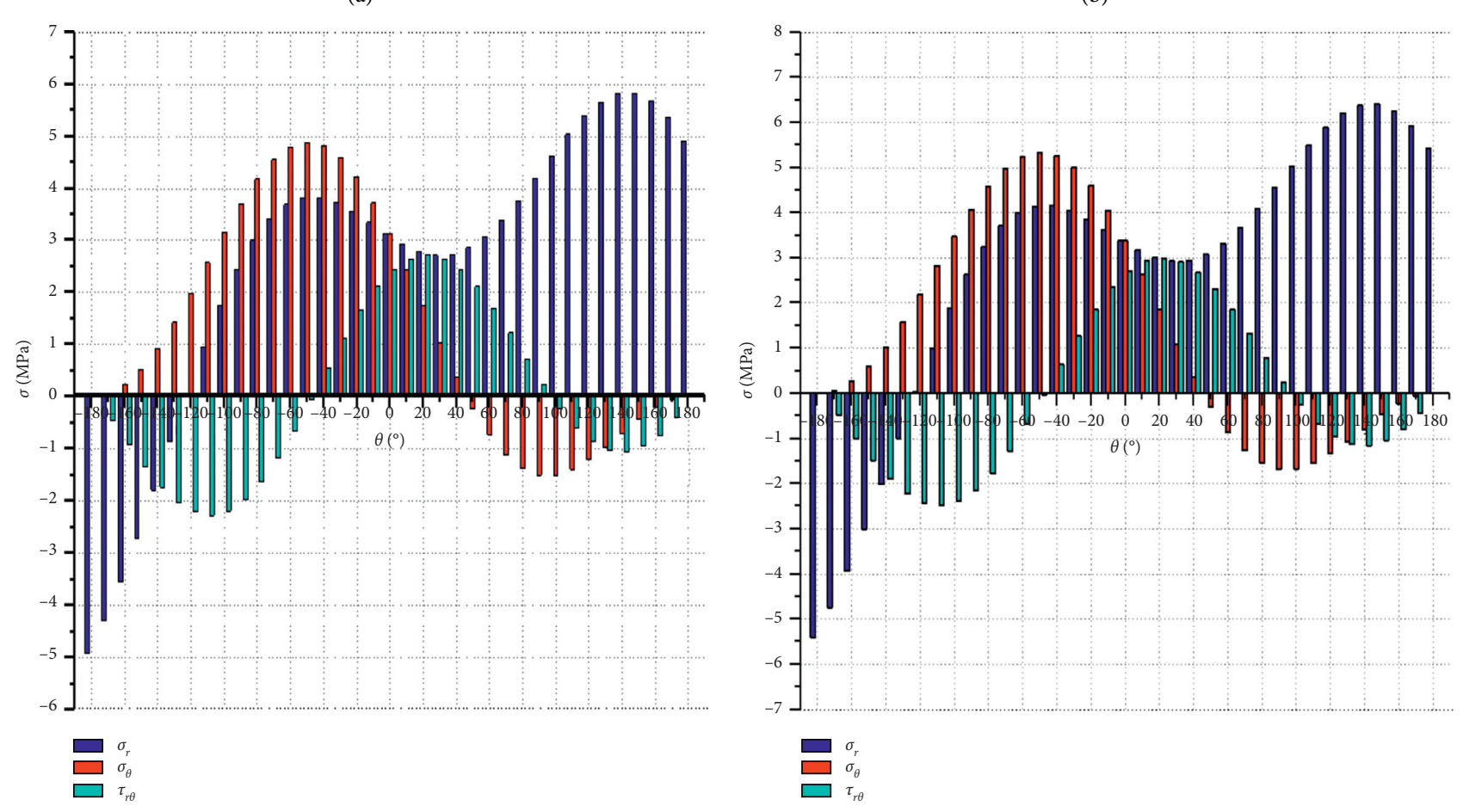

(c)

(d)

Figure 7: Continued. 


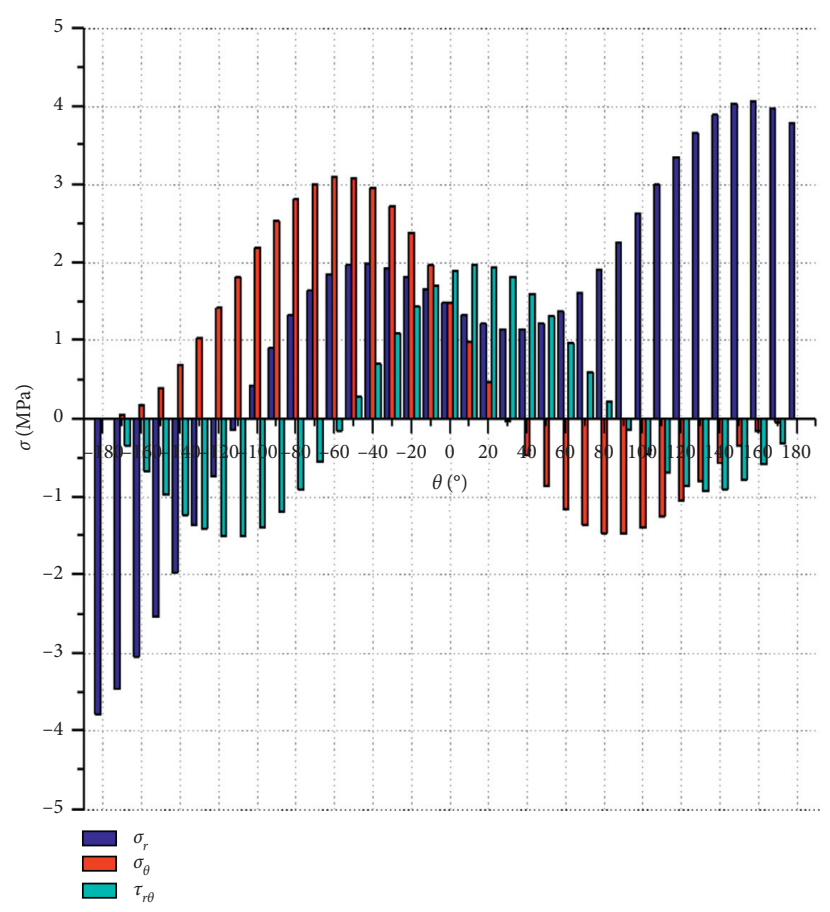

(e)

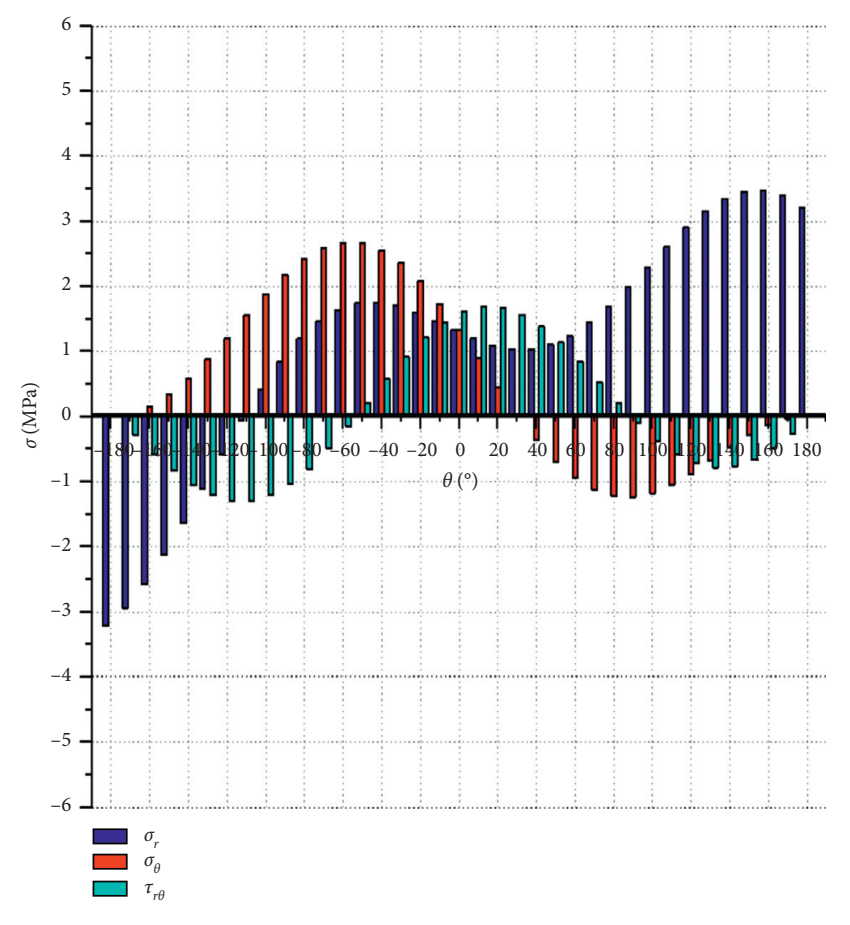

(f)

Figure 7: Variation curves of circumferential tensile stresses and shear stresses of the fissure specimens with different dip angles. (a) $A$ $1\left(\sigma_{1 \max }=5.57 \mathrm{MPa}\right),(\mathrm{b}) A-2\left(\sigma_{1 \max }=5.9 \mathrm{MPa}\right),(\mathrm{c}) B-1\left(\sigma_{1 \max }=4.1 \mathrm{MPa}\right),(\mathrm{d}) B-2\left(\sigma_{1 \max }=5.42 \mathrm{MPa}\right),(\mathrm{e}) C-1\left(\sigma_{1 \max }=4.56 \mathrm{MPa}\right)$, and $(\mathrm{f}) C-2$ $\left(\sigma_{1 \max }=4.03 \mathrm{MPa}\right)$.

mentioned I-II tension-shear or compression-shear combined fissures.

According to the approximate fracture criterion [24], we assumed that the crack length inside the rock mass is $2 \alpha$, and the stress polar coordinate expression of the front edge of the combined fissures in this test is as follows:

$$
\begin{aligned}
\sigma_{r} & =\frac{1}{2 \sqrt{2 \pi r}}\left[K_{\mathrm{I}}\left(3-\cos \theta \cos \frac{\theta}{2}\right)+K_{\mathrm{II}}(3 \cos \theta-1) \sin \frac{\theta}{2}\right] \\
\sigma_{\theta} & =\frac{1}{2 \sqrt{2 \pi r}} \cos \frac{\theta}{2}\left[K_{\mathrm{I}}(1+\cos \theta)-3 K_{\mathrm{II}} \sin \theta\right] \\
\tau_{r \theta} & =\frac{1}{2 \sqrt{2 \pi r}} \cos \frac{\theta}{2}\left[K_{\mathrm{I}} \sin \theta+K_{\mathrm{II}}(3 \cos \theta-1)\right] .
\end{aligned}
$$

In view of the crack-tip stress field theory, we analyzed the stress field and the failure mode of the two-fissure structure. Since this research adopted bidirectional loading, $\sigma_{2}$ is not zero. According to the specimen parameters and the definition of stress intensity factor [25], the stress intensity factors of I and II cracks in this test are taken as follows:

$$
\begin{aligned}
K_{\mathrm{I}} & =\sqrt{\pi a}\left(\sigma_{1} \sin ^{2} \beta+\sigma_{2} \cos ^{2} \beta\right) \\
K_{\text {II }} & =\sqrt{\pi a}\left(\sigma_{1}-\sigma_{2}\right) \sin \beta \cos \beta,
\end{aligned}
$$

in which $\alpha$ is $1 / 2$ of the crack length, and $\beta$ is the angle between the fissures and the axis of the principal stress $\sigma_{1}$.
Based on (6), we obtained the theoretical solution near the tip of I-II fissure structure, and thus the relationship between the fracture angle $\theta_{0}$ and the fissure angle $\beta$ is as follows [26]:

$$
\sin \theta_{0}+\left(3 \cos \theta_{0}-1\right) \cot \beta=0 .
$$

Thus when the fissure angle $\beta$ is given, the corresponding fracture angle $\theta_{0}$ can be obtained, based on which the new propagation direction can be inferred.

The two-fissure specimens in current research failed in complicated ways. In order to explore the application of the crack-tip stress field theory in rock mass with multiple structural planes, we set the following parameters according to the sizes of the specimens and the angles of the precut fissures and utilized software programming for visualized and more direct analysis of the distribution of tectonic stress field with two fissures and different dip angles.

Since the fissure dip angle and the angle between the fissures and the principal stress complement each other, we let the fissure angles $\beta$ of groups $A, B$, and $C$ be $60^{\circ}, 45^{\circ}$, and $30^{\circ}$, respectively, and the confining pressure $\sigma_{2}$ be $1 \mathrm{MPa}$. And we let the axial compression $\sigma_{1}$ be $0 \sim \sigma_{1 \max } \mathrm{MPa}\left(\sigma_{1 \max }\right.$ is the axial stress in the critical failure state), and substituted it in (5) and (6) at every $1 \mathrm{MPa}$. Then we obtained the variation curves of the radial tensile stresses $\sigma_{r}$, circumferential tensile stresses $\sigma_{\theta}$, and shear stresses $\tau_{r \theta}$ of the fissure structures with different dip angles, as shown in Figure 7. 
By comparing and analyzing the stress variation curves at the tip of the precut fissures with different dip angles, the following can be found:

(a) There is are similarities in the variation trends among the curves of radial tensile stresses $\sigma_{r}$, circumferential tensile stresses $\sigma_{\theta}$, and shear stresses $\tau_{r \theta}$ at the fissure tips of the 6 groups of specimens, all of which are smooth curves with fluctuations. The differences lie in that all of the radial tensile stress curves feature two peak directions of about $-55^{\circ}$ and $140^{\circ}$, while the two peak directions in circumferential tensile stress curves are $-60^{\circ}$ and $90^{\circ}$, with almost the same positions where the negative angular peaks appear in both curves. In addition, three peak directions appear in the shear stress curves, which are about $-110^{\circ}, 10^{\circ}$, and $120^{\circ}$.

(b) Based on the data in Figure 7 and Table 3, it can be found that the angle at the peak of circumferential tensile stress is basically consistent with that of the development of the main crack on the specimen, while secondary coplanar cracks appear at the peak of shear stress. The stress concentration occurs at the tip of the specimen under the external load, and at the location of the most concentrated circumferential tensile stress, the main crack is most easily to be induced, which is also the location of radial tensile stress concentration. It can be inferred that the main crack propagation and the subsequent failure of the specimen are caused by the combined action of the maximum circumferential tensile stress and the maximum radial tensile stress at the fissure tip.

\section{Conclusions}

In order to investigate the failure law of rock mass with cracks under biaxial stress, we employed the true triaxial test system of coupled stress-seepage to carry out two-dimensional loading on the rock-like specimens with two fissures. Based on this, we then discussed the crack propagation law and failure mode of the specimens and the effect of stresses at the tip of the fissures on crack propagation and evolution in view of the fissure tip stress field theory. The major conclusions are as follows:

(1) Comparing the compressive strengths of the specimens reveals that the compressive strength of intact specimen is higher than that of the one-fissure specimen and much higher than that of the twofissure specimen, which indicates that fissure precutting can reduce the mechanical properties such as the rock mass strength, and the more the fissures and cracks are, the lower the specimen strength is, and the more easily the specimen fails.

(2) The overall strengths of the two-fissure specimens with the fissure angles of $30^{\circ}$ and $45^{\circ}$ increase with the increase of the rock bridge dip angle, while the overall strength of the specimens with the fissure angle of $60^{\circ}$ decreases with the increase of the rock bridge dip angle. Thus, with other certain parameters, the overall compressive strength of the twofissure specimens is closely related to the fissure dip angle and the rock bridge dip angle. Let $\theta$ be the critical fissure angle, and then there is $45^{\circ}<\theta<60^{\circ}$. When the fissure dip angle $\alpha$ is smaller than $\theta$, the overall strength of the specimen increases with the increase of the rock bridge dip angle $\beta$; and when $\alpha$ is bigger than $\theta$, the overall strength of the specimen decreases with the increase of $\beta$.

(3) Most two-fissure specimens fail mainly under the combination of compression-shear and tensionshear with wing cracks, inclined shear cracks, and coplanar shear cracks generated and under the compression-shear with wing cracks and inclined shear cracks generated. When the axial stress reaches about $90 \%$ of $\sigma 1$, it is near the critical state of specimen failure, with the upper and lower fissures penetrated in different ways.

(4) The concentrated stress distribution at the fissure tip on the specimen is basically consistent with the propagation direction of the main crack, and it is easier for the main crack to be induced and penetrated at the position of most concentrated circumferential tensile stress and radial tensile stress at the double-crack tip. In engineering projects, this finding can be utilized to predict the direction along which the new cracks are generated between the fissures with certain fissure structure angle, rock bridge angle, and under certain confining pressure, which may function as a guidance for the studies on failure and instability of structural rock mass.

\section{Data Availability}

The datasets generated and analyzed in the current study may be obtained from the corresponding author upon reasonable request.

\section{Conflicts of Interest}

The authors declare that there are no conflicts of interest regarding the publication of this paper.

\section{Acknowledgments}

This research was financially supported by the National Natural Science Foundation of China (Grant nos. 51604167 and 51974172), the Natural Science Foundation of Shandong Province (Grant no. ZR2019MEE004), and the Support Plan for Outstanding Youth Innovation Team in Shandong Colleges and Universities (Grant no. 2020KJH001).

\section{References}

[1] P. Cao, R. H. Cao, Y. L. Zhao et al., "Propagation-coalescence and rheologic fracture behavior of rock cracks," The Chinese Journal of Nonferrous Metals, vol. 26, no. 8, pp. 1737-1762, 2016. 
[2] C. Zhao, J. Q. Xing, J. L. Niu, and C. C. Ma, "Experimental study on crack propagation of precast fractured rock samples under combined action of water and force," Journal of Rock Mechanics and Engineering, vol. 38, no. S1, pp. 2823-2830, 2019.

[3] W. J. Sun and W. Y. Zhou, "An Elasto-plastic damage mechanics constitutive model for jointed rockmass," Chinese Journal of Rock Mechanics and Engineering, vol. 9, no. 2, pp. 108-119, 1990.

[4] C. Z. Pu, P. Cao, Y. L. Zhao et al., "Numerical analysis and strength experiment of rock-like materials with multi-fissures under uniaxial compression," Rock and Soil Mechanics, vol. 31, no. 11, pp. 3661-3666, 2010.

[5] L. M. Yin, W. J. Guo, and J. T. Chen, "Development of true triaxial rock test system of coupled stress-seepage and its application," Chinese Journal of Rock Mechanics and Engineering, vol. 33, no. s1, pp. 2820-2826, 2014.

[6] G. R. Irwin, "Analysis of stress and strains near the end of a crack extension force," Journal of Applied Mechanics, vol. 24, pp. 361-364, 1957.

[7] X. B. Li, X. Q. He, and H. J. Chen, "Crack initiation characteristics of opening-mode crack embedded in rock-like material under seepage pressure," Chinese Journal of Rock Mechanics and Engineering, vol. 31, no. 7, pp. 1317-1324, 2012.

[8] S. H. Guo, Experimental and Theoretical Study on Fracture of Rock-like Material under Compressive Loading, Central South University, Changsha, China, 2003.

[9] Y. Xue, W. Sun, and Q. Wu, "The influence of magmatic rock thickness on fracture and instability law of mining surrounding rock," Geomechanics and Engineering, vol. 206 pages, 2020 .

[10] Y. Li, W. B. Cai, W. S. Zhu et al., "Experiment and particle flow analysis of crack propagation evolution mechanism under hydraulic coupling," Engineering Science and Technology, vol. 52, no. 3, pp. 21-31, 2020.

[11] W. Yang, Y. Geng, Z. Zhou et al., "DEM numerical simulation study on fracture propagation of synchronous fracturing in a double fracture rock mass," Geomechanics and Geophysics for Geo-Energy and Geo-Resources, vol. 6, no. 4, 2020.

[12] M. F. Cai, Rock Mechanics and Engineering, Science Press, Beijing, China, 2013.

[13] T. B. Zhao, W. Zhang, and S. T. Gu, "Study on fracture mechanics of granite based on digital speckle correlation method," International Journal of Solids and Structures, vol. 193-194, pp. 192-199, 2020.

[14] X. Wu, F. Wang, X. Xi et al., "Experimental study on strength characteristics and fracture mechanism of orthogonal cross fracture rock," Journal of Coal Industry, vol. 45, no. 7, pp. 2681-2690, 2020.

[15] N. Qin, Z. L. Zhangg, X. Z. Feng et al., "Experimental study on uniaxial strength and crack propagation law of fractured rock after creep," Coal Science and Technology, vol. 48, no. 12, pp. 244-249, 2020.

[16] W. S. Zhu, W. Z. Chen, and J. Shen, "Simulation experiment and fracture mechanism study on propagation of echelon pattern cracks," Chinese Journal of Solid Mechanics, vol. 19, no. 4, pp. 355-360, 1998.

[17] J. Cheng and S. S. Zhao, Fracture Mechanics, Science Press, Beijing, China, 2006.

[18] G. P. Li, "The damage models for rock-like materials with microcracks," Chinese Journal of Rock Mechanics and Engineering, vol. 14, no. 2, pp. 107-117, 1995.
[19] R. S. Yang, Y. F. Zhang, L. Y. Yang et al., "Study on the mixing proportion test of similar material gypsum," China Mining Magazine, vol. 22, no. 10, pp. 125-130, 2013.

[20] W. Sun, F. Zhou, J. Liu, and J. Shao, "Experimental study on portland cement/calcium sulfoaluminate binder of paste filling," European Journal of Environmental and Civil Engineering, 2020.

[21] B. T. Shen, Mechanics of Fractures and Intervening Bridges in Hard Rocks, Royal Institute of Technology, Stockholm, Sweden, 1993.

[22] C. E. Fairhurs and J. A. Hudson, "Proposed method draft of ISRM for measuring complete rock stress-strain curve by uniaxial compression test," Chinese Journal of Rock Mechanics and Engineering, vol. 19, no. 6, pp. 802-808, 2000.

[23] J. T. Chen, M. Li, B. B. Cheng et al., "Influence of loading rate on the fracture characteristics of large-size specimen," Coal Geology \& Exploration, vol. 47, no. 5, pp. 163-172, 2019.

[24] S. Y. Li, T. M. He, and X. C. Yin, Rock Fracture Mechanics, Science Press, Beijing, China, 2015.

[25] Y. Q. Song, S. L. Wang, C. Sun, and L. J. Hao, "Similar model test and mechanical analysis of fault structure," Coal Geology \& Exploration, vol. 47, no. 5, pp. 150-156, 2019.

[26] Z. N. Li and J. K. Zhang, Engineering Fracture Mechanics, Beihang University Press, Beijing, China, 2012. 